sciendo

DOI: 10.2478/rae-2021-0018 Review of Artistic Education no. 212021 149-156

\title{
18.THE SECOND SONATA FOR PIANO AND VIOLIN, ÓPUS 6 BY GEORGE ENESCU
}

Raluca Dobre Ioniță ${ }^{149}$

\begin{abstract}
The second Sonata for Piano and Violin, op. 6 by George Enescu marks the beginning of a long road of assimilation and synthesis of the Romanian folklore elements and of the way of expression "in Romanian popular character", transposed on the characteristics of the universal language. Without knowing the authentic folk art from a scientific point of view, Enescu was deeply influenced, shaping his entire artistic personality. He consciously assimilated popular music by generalizing some essential folkloric principles, which he later organized in a personal vision. The innovative elements of the Enescian musical language are transposed in the free rhythm, the heterophonic construction, the complexity and subtleties of dynamics and agogics, the timbre color, as well as in the synthesis between freedom and rigor in the creative and interpretive act.
\end{abstract}

Key words: Enescu, Sonata, piano, violin, analysis

\section{Introduction}

The Romanian national musical culture from the first half of the 20th century is closely linked to the humanistic values of national and universal art. Enescu's creation follows a path of stylistic and conceptual maturation that starts from the influences of the great masters of classical music (the architecture of forms and polyphonic writing of Beethoven's final creations, the monumentality and grandiose character of Brahms's constructions, Wagnerian chromatisms, the cyclical character of Franck's themes, the modalism and simplicity of the harmonic structures from Fauré) and continues with the personal aesthetic expression, in which he synthesized elements belonging to both the tonal and modal language, as well as the diatonic and chromatic one. In addition to these very different stylistic sources, Enescu tried to include elements of Romanian popular culture.

\section{Discussions}

The Second Sonata for piano and violin marks the beginning of a long road of assimilation and synthesis of the Romanian folk elements and of the way of expression "in Romanian popular character", grafted on the characteristics of the universal language. Without knowing the authentic folk art from a scientific point of view, George Enescu was deeply influenced, shaping his entire artistic personality. Enescu consciously assimilated popular music by generalizing some essential folkloric principles, which he later organized in a personal vision. The innovative elements of the Enescian musical language are transposed in the free rhythm, the heterophonic construction, the dynamic and agogic complexity and subtleties, the timbre color, as well as in the synthesis between freedom and rigor in the creative and interpretive act.

Among the elements with national specificity within this work, we mention

${ }^{149}$ Lecturer PhD., "George Enescu” National University of Arts from Iași, Romania, email: rallutz@yahoo.com 
the harmonic minor scale with the fourth degree altered upwards (also called fiddle scale), the modal inflections made by lowering the second degree (from the main theme of the middle part) and the piano style, in the sense of imitating the specific accompaniment of the cymbal (third part, couplet B).

Through the Second Sonata for piano and violin, Enescu demonstrates that the sonata, as a European and universal musical form, can cover both traditional clothing and national language. The work, dedicated to Joseph and Jacques Thibaud, was completed in Sinaia, in November 1898. The sonata was performed in first audition in Paris, in 1900 by Jacques Thibaud on violin and George Enescu on piano. The piano-violin couple has recorded throughout the history of the European and universal sonata the most representative works of chamber instrumental music. The violin is a European instrument used in Romanian folk practice with fiddle specifics and the piano is a classical European instrument that manages to imitate very well the timbre of the cymbal (musical instrument with beaten strings, used mainly in folk music).

\section{Results}

The Sonata consists of three movements: first part - Assez mouvemente, the second part - Tranquillement and the third - Vif. The first movement begins in the key of $F$ minor and is organized in the form of a sonata without development. The Exposition (m. 1-64) includes: the main theme (marked with A), consisting of three sentences: A (m. 1-16), A1 (m. 17-23) and A2 (m. 24-29), the Bridge (m. 30$37)$ and the secondary theme (m. 38-64), also organized in three sentences: B (m. 38-41), B1 (m. 42-52) and Bv (m. 53- 64).

The main theme, presented in unison by the two voices participating in the construction of the musical development (piano and violin), is considered by many analysts as the "cornerstone" of the whole work. The principle of organization of the sound material, the unison, represents in the Enescian conception the primordiality of the melody in relation to the harmony. The balance of the minor third - major third, semitone - minor third (or enharmonic, semitone - magnified second) intervals and the ambiguity of the rhythm (which takes place in binary and ternary rhythmic structures in the measure of 9/4) accentuate the anxiety of this beginning:

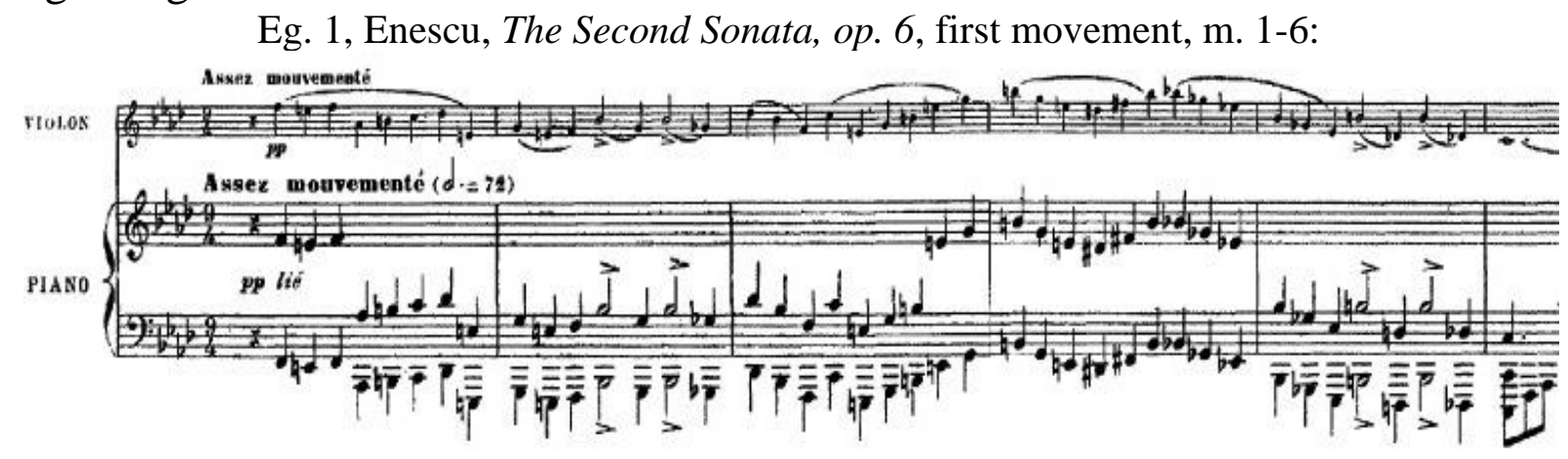

The voices intertwine in an uninterrupted flow, supported by: dynamic waves, accents on secondary beats and special rhythmic overlaps. Both instruments are used to the fullest technically, but especially expressively. The tonality itself ( $F$ minor) is difficult and uncomfortable especially for the violin 
technique.

In order to get as close as possible to the Enescian aesthetic truth and to discover the interpretive meanings of the musical text, the technical difficulties of this score must be overcome. They appear even in the serpentine exposition of the first sentence of the main theme and can be studied by the controlled dosing of the pressure on the whole development of the bow, as well as by the balanced and uninterrupted support of the melody, which takes place in very light nuance (pianissimo).

For the interpretive unity of the musical discourse, it is recommended that the two partners study in a very rare tempo, in a nuance reduced in intensity, avoiding inappropriate breathing that may occur due to technical difficulties. Performers must feel and think like a whole, anticipate each other's interpretive intentions, so that the two voices intertwine in a perfect symbiosis. The tension of the musical discourse gradually evolves towards the culmination of the main musical idea, which is presented by both instruments in the form of a minor harmonic descending scale with the fourth degree altered upward, in parallel octaves, also called the fiddle scale:

Eg. 2, Enescu, Second Sonata, op. 6, first movement, m. 14-16

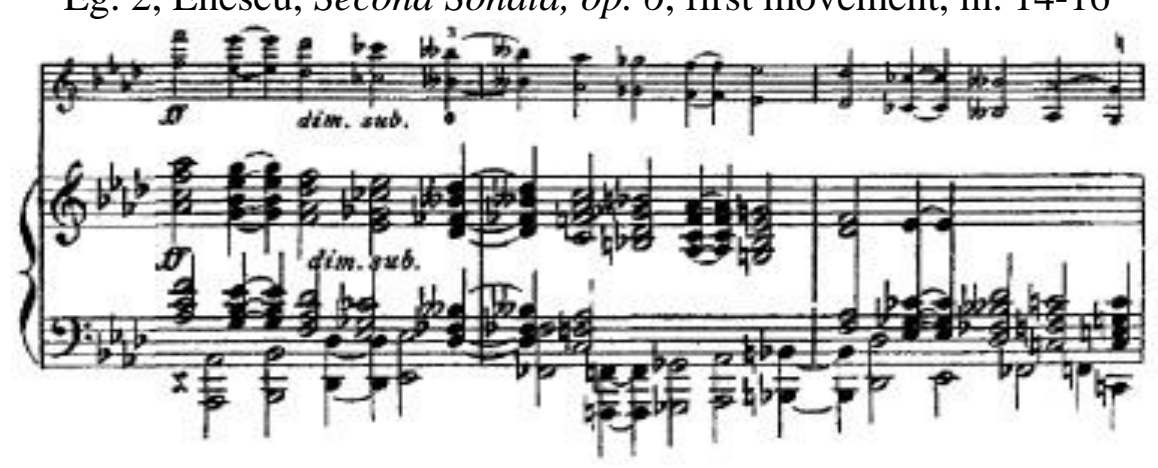

The Bridge (m. 30-37), formed by rhythmic and melodic elements characteristic of the main theme (in A minor), has the role of completing the main thematic group rather than contrast, as it occurs in the structure of the traditional sonata form. The nuance is an element highly dramatized and the dynamic variability determines the acquisition of a good technique of the bow.

The secondary theme (m. 38-64), related to the first theme in terms of musical content, presents a romantic atmosphere, emphasized by Enescu through the technique of overlapping the binary rhythm (quadruplet) with the ternary one. One of Enescu's expressive means of violin refers to the species of bow feature called louré, which actively participates in shaping the expressiveness of musical discourse through the technique of reproducing sounds within the same bow. The main thematic ideas dialogue continuously and merge into a unitary whole, culminating towards a much amplified and dynamically contrasting conclusion.

The Development (m. 65-79) is replaced by an evolution of the secondary theme, because in the Exposition no contrasting elements were presented, which would require a thematic confrontation. This contradictory phenomenon goes out on its own, determining at the same time the structural and thematic unity of the musical content.

In the Recapitulation (m. 80-134), the initial tonality is brought back ( $F$ 
minor), presented very discreetly on the violin ( $p p)$, while the piano keeps the technical character of the previous passage (eight notes). If the first sentence is exposed in $F$ minor, the second sentence is found in the tonality of $C$ minor. The dramatic tension of the musical discourse is achieved through thematic overlaps, imitations, dialogues that will culminate in a strong dynamic contrast (fff) concluded, as in the Exposition, through the fiddle scale. The return of the secondary theme in the $F$ minor key will not bring essential changes and will follow its course as in the Exposition.

Coda (Très vif, m. 135) again presents the main theme in unison, in binary rhythm; it has a culminating evolution (fff) which is abruptly interrupted by a crown break (m. 147). Finally, fragments of the leading theme are exposed for the last time in the form of resigned and painful sobs. The many technical difficulties we encounter in the violin score affect the technique of both hands. We refer here to: the predominant use of uncomfortable double strings (such as tenth and ciphered eights) that require the extended position of the left hand, varied control of the bow pressure on the strings, diversification of sound attack, differentiation of the used quantities of the bow, accents distributed on secondary beats, highlighting dynamic contrasts, achieving slightly flattened intonational accuracy, maintaining rhythmic balance and uninterrupted support of musical phrasing.

The second part of the Sonata (Tranquillement) continues the intimate character specific to the first movement, in a quieter development, strongly imprinted by the archaic Romanian style. The musical form of this part is built on the structure of a large, tripartite lied, in which the return of the main idea is varied. The first section (m. 1-43) is organized on a tripartite lied and the first musical idea unfolds slowly, like the sonority of a swing song, having an asymmetrical phrasal development. The piano accompaniment is discreet and the violinist must warm the atmosphere with a calm, quiet vibrato and the natural and continuous flow of the bow, trying to create a dusty rustic atmosphere:

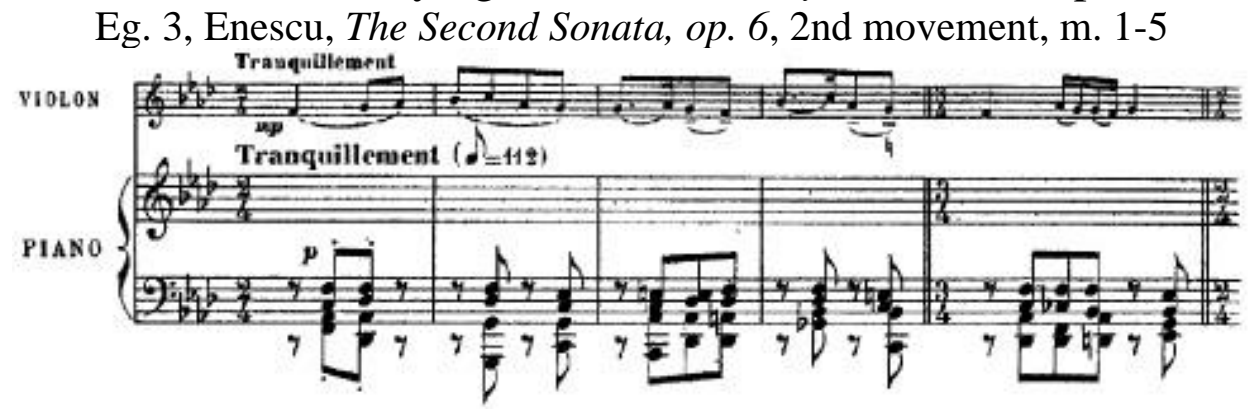

A two-measure passage on the dominant of the $F$ minor key prepares the return of the Theme (m. 18), presented by the piano; during this time, the violin maintains a quiet counter melody. At measure 23, the theme presented by both instruments returns in unison. From measure 27, the performers dialogue imitatively through descending sequences, structured in rhythmic values of sixteenths. The original song returns to measure 33; later, it will be varied by the violin through an equal and monotonous rhythmic and melodic cell from the atmosphere of which a new melody will emerge, which marks the beginning of the second stanza.

The middle section (m. 44-83), Un peu plus lent, reveals a melodic contour 
sprinkled with intervals typical of popular modes (magnified second), organized rhythmically on a binary structure; the rhythmic-melodic content of the musical development has a slight resemblance to the melodic cell specific to the first movement of the Sonata, creating the thematic unity of the work. The sound discourse is gradually energized, both from an agogic and dynamic point of view, a phenomenon that leads us to the culmination of the whole section (fortissimo), immediately followed by the decrease of the general sonority to an internalized nuance, cadenced in $B$ flat major.

The main theme, brought back twice with an enlargement, in the key of $G$ minor, prepares the return of the $F$ minor tonality and implicitly the Reprise (m. 84-141). First presented on the piano, the theme will be taken over by the violin in pianissimo (with mute), in the measure 100. The intimate dialogue between the two instruments is gradually extinguished. The last struggle of the theme is sketched by the violin, in a barely perceptible sonority, in the movement of a very small tremolo; the piano completes the atmosphere with a descending chromatic intervention that gradually becomes thinner. In the Coda (m.124-141), the violin is left alone to unravel the end of this story, built like a spontaneous, improvisational inspiration, which wanders with twists and fragments from the theme, so that in the end, to rest its finished expression on two prolonged chords, structured on parallel perfect fifths (natural G - natural D, natural A - natural E).

The Third part of the Sonata (Vif), structured in the form of a rondo-sonata, creates new expressive valences characterized by the presentation of a single pregnant theme, the rest of the thematic ideas coming from the greater or lesser transfiguration of those of the previous movements, thus determining the thematic unit of the content. The tonal unit of the work is achieved at the end of it by bringing the key $F$ major. The first stanza (m. 1-49) surprisingly debuts on the piano in $D$ minor with a sprinting and exuberant theme:

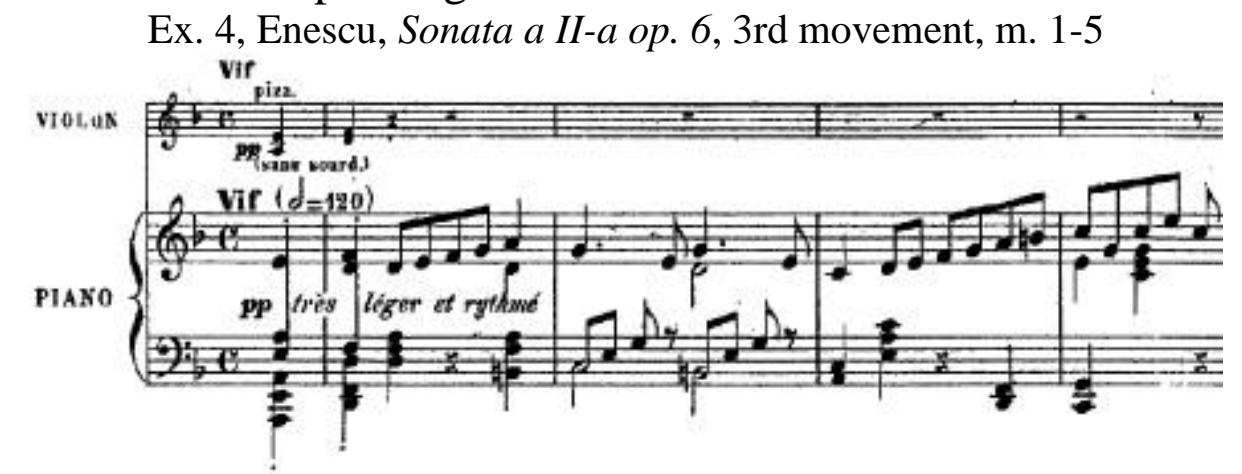

From a tonal point of view, refrain follows an interesting path that oscillates during the first section between different contrasting tones $D$ minor $C$ major $F$ major $C$ major. The dialogue between the two instruments is built through different polyphonic composition techniques (imitations, canons, stretto), a phenomenon that will accentuate the exuberant character of the musical development and the intense processing of the thematic content.

The third movement of the Sonata reveals a dizzying thematic development; the violinist must ensure the uninterrupted fluency of the musical text by overcoming the technical problems of the right hand (spiccato technique, the adjust of the bow pressure, the fuse of the bow during string exchanges) and the 
left hand (accuracy of intonation on double strings, adaptation of the various expressive requirements, the malleability and ease of position exchanges). Performers must create surprising dynamic effects and not lose sight of achieving a sound appropriate to the musical expression.

The strong rhythm in the piano score, underlined by the indication très sec (m. 50), announces the appearance of couplet B (m. 53-115). The violin brings to the fore the main theme of first Part, in augmented values, carrying the dedication très vibrante et à plein son; the tumultuous and vibrant character of the theme (exposed in $C$ minor) is fundamentally different from the character of the themes from the first movements of the Sonata. This musical idea will be interrupted in some places by the characteristic motif of the refrain, presented in the form of a signal, during four repetitive measures (m. 64-67). The vibrant character of the theme will be transfigured by the rhythmic dynamization of the melody.

The leading theme of the Sonata evolves impressively from an expressive point of view, being transfigured in different hypostases: at first restless, sometimes passionate, in the middle movement it becomes nostalgic and finally it acquires an alert character (m. 78). The melodic fluidity is supported by the piano through an accompaniment organized in small and equal values (sixteenths), similar to the fiddle imitation of the cymbal. While the violin supports the new character of the theme, in the bass of the piano score (tres marquée la basse quoique $p$ ) appear thematic elements characteristic of the main theme of the middle movement (m. 103). This section is concluded by the insistent return of the characteristic refrain signal, which demonstrates once again the Enescu polyphonic mastery of playing two different themes without visible artifice.

The refrain (m. 116), presented this time by the violin, is slightly varied in intimate nuance ( $p p$ léger); in the piano score, a new song appears, born from the main theme of the first part, in the E minor key. From this moment, we will follow the thematic intertwining characteristic of the three movements of the Sonata, in a close and complex development. At mark 23 (from the score), the main theme from the middle part of the Sonata reappears in bass, in D major, amplified and supported by the violin through a variant of the secondary theme from first part, which announces the end of Exposition, in $C$ major.

The couplet C (m. 155-189) begins in the key of $B$ flat major with the indication Un peu plus lent. In this section, Enescu overlaps the theme of section B of the second movement (on violin) with the theme of section A on the same part (on piano). The multiple indications of dynamics, agogic and character in the scores of both instruments reveal very accurately the interpretive intentions of the author, who wants the two performers to create the symbolic unity of the two themes underlined by a very expressive atmosphere, similar to the round sonority of a bell. The end of this theme brings to attention the main theme of first movement; a wide transition follows in which motifs from the second part are processed in the tonalities $C$ major - $C$ minor, which will prepare the anacrusis of the Reprise in $G$ minor, namely the second degree of the $F$ major key. This central couplet exposes a thematic material concentrated in an exuberant atmosphere.

The refrain (m. 190-241) returns in a new key ( $F$ major), being slightly 
varied from a thematic point of view. Stanza B (m. 242) appears in fminor tonality and follows almost the same course as in Exposition, which determines that the structure of the final movement looks like this:
A
A
$\mathrm{C}$
A
$\mathrm{B}+$ Codă
$\begin{array}{llll}\text { m. 1-49 } & \text { m. 50-115 } & \text { m. 116-154 } & \text { m. 155-189 }\end{array}$
m. 190-241
m. 242-314 m. 315-345
D minor C minor E minor B flat Major
- F Major
F minor
F Major

Enescu will eliminate the last refrain from the typical form of the rondosonata in order not to create monotony in the musical development. In the Code, the main theme of the second movement in its pure form returns for the last time, then, through a sudden passage, but slightly anticipated by the arpeggiated characteristic touch of the piano, the violin attacks in the acute register the fiddle scale of the main theme, characteristic for the first movement of the Sonata; this descent will be gradually calmed by a long pedal to C (m. 328-335). The cyclic unity of the Sonata is strengthened by the conclusive return of the generating theme (m. 336-345), transfigured in terms of musical content and played in unison in a very low sonority ( $p p p p)$.

Enescu's music is between two ways of structuring the sound material, the chromatic technique and the cyclic one, which are used to obtain the thematic unity in a single melodic line. The use of chromatisms did not determine Enescu to give up the tonal system in favor of serialism, although sometimes his musical language passes into the plane of atonalism. The complexity of the language results from the finesse of the dynamic and agogic notations, as well as from the timbre color elements (the quarter tones and the variety of the attack modalities). The predominant sonority emerges from the emotional warmth transposed into the quiet nostalgia of longing. The coexistence of several spiritual calls is underlined by the transitions from the tumultuous states to those of deep silence, fact that determines both instrumentalists to render this work with suppleness and spiritual and artistic mobility.

Specific intonations are made by timbre effects (ascending or descending semitonal glissando, variable vibrato, with wide or narrow amplitude and slow or fast frequency, depending on the requirements of the musical text, the color of the free strings). Enescu's interpretation is characterized by the malleability of nuances and modes of attack, which can be interpreted in various ways, so as to obtain special musical and aesthetic meanings. Enescu is the one who universalized the poetic image of emotions through violinistic means specific to our popular ethos. One of the technical means that are put at the service of the Enescu musical expression, the luoré, is important in the imitative rendering of the recited speech, associated with the quadruplet rhythmical formula. The application of fingering through extensions and contractions emphasizes the expressiveness of the musical discourse.

The sound of the violinist must be warm, supported by a clear and lively articulation, causing a deep awareness of the instrumental touch. The vibrato must fit between the pale color of the white sound and the energetic and passionate turmoil of the fire from the depths. The sound voltage must be sustained along the entire length of the bow. The right hand must be supple, elastic, but also vigorous. We consider it important to choose a suitable tempo, so that the musical 
expression is primordial and the instrumental technical means are subordinated to it. The imitation of Enescu's interpretation must be avoided so as not to degenerate into epigonism and lack of originality.

\section{Conclusions}

The sound pulsations inside the music are followed by the composer George Enescu and as a performer, a relationship that has contributed immensely to the particularity and essentiality of the stylistic elements belonging to chamber music. The various possibilities of expression determine the density of instrumental writing, the transparency of the sound image and the fluency of musical ideas. The innovative elements of the Enescian musical language are transposed in the free rhythm, the heterophonic construction, the dynamic and agogic complexity and subtleties, the timbre color, as well as in the synthesis between freedom and rigor in the creative and interpretive act.

\section{References}

1. Bălan, George, (1962), George Enescu: Mesajul - Estetica, Editura Muzicală a Uniunii Compozitorilor din R.P.R., București

2. Bentoiu, Pascal, (1984), Capodopere enesciene, Editura Muzicală, Bucureşti

3. Ghircoiaşiu, Romeo, (1981), Studii enesciene, Editura Muzicală, București

4. Manoliu, George, (1986), George Enescu: poet si ganditor al viorii, Editura Muzicală, București

5. Rădulescu, Mihai, (1971), Violonistica enesciană, Editura Muzicală, București 